\title{
Measurements of aerosol intensive properties over Visakhapatnam, India for 2007
}

\author{
K. Niranjan ${ }^{1}$, B. Spandana ${ }^{1}$, T. Anjana Devi ${ }^{1}$, V. Sreekanth ${ }^{2}$, and B. L. Madhavan ${ }^{1}$ \\ ${ }^{1}$ Department of Physics, Andhra University, Visakhapatnam 530 003, India \\ ${ }^{2}$ Space Physics Laboratory, Vikram Sarabhai Space Centre, Trivandrum 695 022, India
}

Received: 7 August 2010 - Revised: 1 March 2011 - Accepted: 15 March 2011 - Published: 10 June 2011

\begin{abstract}
Information on the aerosol intensive properties like Single Scattering Albedo (SSA) and asymmetry parameter are very limited, particularly over the peninsular India, though extensive reports are available on the aerosol bulk properties. In view of the importance of these parameters in evaluating the aerosol radiative forcing, we present for the first time the temporal variation in SSA with measurements on aerosol absorption and scattering coefficients over Visakhapatnam $\left(17.72^{\circ} \mathrm{N}, 83.32^{\circ} \mathrm{E}\right.$; located on the east coast of India) for the year 2007. The inferred SSA was in the range of 0.65 and 0.9 with an annual mean of $0.76 \pm 0.013$ and with a probable value of 0.80 , indicating a marginal atmospheric warming over the region. The mixed layer contribution to column Aerosol Optical depth is found to be $35 \%$ in summer while it is well above $35 \%$ in winter, indicating the confinement of aerosol within the boundary layer during winter. The asymmetry parameter which represents the angular scattering in radiative forcing estimation is found to be around $0.65 \pm 0.1$ for the location. The day to day variability in SSA is found to be well correlated with the variations in surface BC mass concentrations and/or the relative dominance of the fine/coarse mode aerosol. The results are discussed in light of the aerosol physical and optical properties and the asymmetry parameter.
\end{abstract}

Keywords. Atmospheric composition and structure (Aerosols and particles) - Hydrology (Anthropogenic effects) - Meteorology and atmospheric dynamics (Radiative processes)

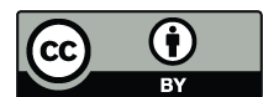

Correspondence to: K. Niranjan (niranjankandula@hotmail.com)

\section{Introduction}

Characterization of aerosol radiative effects has been a challenging task due to large spatial and temporal variability of aerosol species on regional as well as global scales. The available accuracy of aerosol characterization is not often significant due to the lack of detailed knowledge of optical properties of aerosols (Dubovik et al., 2002). Estimation of aerosol induced solar flux changes requires information about the optical properties such as aerosol optical depth, Single Scattering Albedo (SSA), and asymmetry parameter (Haywood and Shine, 1995; Russell et al., 1997; Andrews et al., 2006). Generally four types - viz. urban industrial, biomass burning, desert dust, and marine origin aerosols are associated with different sources and emission mechanisms and are expected to exhibit significant differences. But most of the time a given continental environment is a mixture of two or more of the above species, making it difficult to generalize the limited observations. The optical properties of urban and industrial aerosols demonstrate a significant variation depending on the complex combination of natural and anthropogenic fraction influencing the aerosol formation and evolution (Dubovik et al., 2002). For a given optical depth, the top of the atmosphere radiative forcing critically depends on aerosol backscatter fraction and SSA (Haywood and Shine, 1995; Anderson et al., 1999). SSA is an important property since it's value determines the net cooling or heating of the atmosphere (Hansen et al., 1997). In addition, though it is said that aerosols with SSA greater than 0.85 generally cool the atmosphere while those with less than 0.85 warm the terrestrial atmosphere (Takemura et al., 2002), the critical value of SSA, where cooling shifts to heating, depends on the surface albedo, optical depth, and the asymmetry parameter (Kassianov et al., 2007).

Though extensive measurements are being made over the Indian region and the adjoining oceans for establishing the

Published by Copernicus Publications on behalf of the European Geosciences Union. 
Table 1. Values of SSA over parts of India as reported in literature.

\begin{tabular}{llll}
\hline Location(s) & SSA range/mean & $\begin{array}{l}\text { No. of locations/duration } \\
\text { of the measurements }\end{array}$ & Reference \\
\hline Central India & 0.75 to 0.89 & 10 (spatial) Feb 2004 & Ganguly et al. (2005) \\
Banglore & 0.73 & Oct to Dec 2001 & Babu et al. (2002) \\
Delhi & 0.6 to 0.8 & Dec 2004 & Ganguly et al. (2006) \\
Delhi & 0.74 to 0.84 & Mar to Jun 2006 & Pandithurai et al. (2008) \\
\hline
\end{tabular}

aerosol climatology and its effects at the regional and global scale, measurements on SSA, and asymmetry parameter are very sparse over land in this region. Nair et al. (2008) reported the spatial distribution and spectral characteristics of SSA over Bay of Bengal inferred from ship-borne measurements, which fall between 0.84 and 0.96 with distinct differences between northern and southern Bay of Bengal. Satheesh and Lubin (2003) reported that over oceanic regions, even at moderate winds of $6-10 \mathrm{~m} \mathrm{~s}^{-1}$, the shortwave forcing reduces by $\sim 45 \%$ due to the dominance of sea salt aerosols. Over New Delhi, Pandithurai et al. (2008), reported that the SSA changed from 0.84 to 0.74 from March to June, indicating the increased contribution from a mixture of anthropogenic and dust absorbing aerosol and the effect of the non local dust aerosol transport during the month of June. Measurements over central India showed an overall increasing trend towards the end of winter, indicating unequal changes in source strength and/or removal process of absorbing and scattering aerosols (Ganguly et al., 2005). Thus, the aerosol properties over a location are dependent both on the local sources as well as on the contribution from aerosol species transported from non local sources to the observational site. Table 1 presents the SSA values derived at different sites in India. These measurements are representative for very brief periods. Due to the importance of characterizing the aerosol intensive parameters in the outflow regions from the Indian sub-continent, we present here results of comprehensive investigations carried out on temporal characteristics of the aerosol SSA and the asymmetry parameter at Visakhapatnam, a coastal urban environment representative of the aerosol characteristics over eastern peninsular India. Aerosols vary considerably in their properties that affect the extent to which they absorb and scatter radiation and thus different types may have a net cooling or warming effect. However, not many systematic and accurate measurements exist on the absorption and scattering coefficients. Simultaneous and extensive measurements of these parameters were made at Visakhapatnam and the data for the year 2007 is used in the present study.

Visakhapatnam $\left(17.72^{\circ} \mathrm{N}, 83.32^{\circ} \mathrm{E}\right)$ is an industrial site on the east coast of India located in the air mass pathways from the peninsular India into Bay of Bengal (Niranjan et al., 2007, 2008; Madhavan et al., 2008). Earlier studies on aerosol physical properties such as aerosol optical depth and size distributions have shown that seasonal dependence of aerosol properties well correlate with the synoptic wind direction and mesoscale processes like land and sea breeze (Niranjan et al., 2004). It should also be mentioned that the station is dominated by urban population, and events like biomass burning and crop waste do not take place in the near vicinity of the station to produce an appreciable change in the seasonal characteristics. Measurements of surface Black Carbon (BC) mass concentration show that it is dominated by fossil fuel sources with no indication of any other strong anthropogenic source (Sreekanth et al., 2007) and that the BC mass fraction was consistently $10 \%$ of the total fine mode particle mass as measured from collocated near-surface size segregated aerosol mass size distributions using a Quartz Crystal Microbalance, which indicates that the BC aerosol is well mixed in the ambient fine mode aerosol. Aerosol back scatter vertical profiles measured using a Micro Pulse LIDAR at Visakhapatnam show high altitude aerosol layers above the boundary layer in the height region between 1.6 to $5 \mathrm{~km}$ during the summer months (Niranjan et al., 2006). The air mass origin forming the layers originates from Arabia during $60 \%$ of the cases, with optical properties suggesting a significant fraction of dust aerosol in the layer, while in the remaining cases the air mass originates either from the Indian sub-continent or from Bay of Bengal.

Observations in aerosol extensive properties such as the extinction coefficient typically show that their variability is large with altitude, while the intensive properties such as SSA and asymmetry parameter show less variability with altitude (Kassianov et al., 2007). It is usual to derive the SSA both from column integrated optical measurements from ground based and satellite data and it is important to assess whether the in-situ measured SSA is applicable to column integrated estimation. In view of these aspects we have presented here the temporal characteristics of SSA during the year 2007 and its relation to the surface and column integrated aerosol physical and optical properties at Visakhapatnam. 


\section{Data and methodology}

Aerosol scattering coefficient, absorption coefficient, aerosol spectral optical depths, and aerosol near surface mass size distribution are being measured at Visakhapatnam on a routine basis. The data for the year 2007 were used in the present study to assess the optical state of the atmosphere over this location. Aerosol scattering coefficient was measured using an integrating 3 colour Nephelometer (TSI Incorporated model No: 3563 ) at $450 \mathrm{~nm}, 550 \mathrm{~nm}$, and $700 \mathrm{~nm}$. Details of instrument and calibration procedures are available in Anderson et al. (1996). The instrument directly measures the total scattering (from $7-170^{\circ}$ ) and hemispheric back scattering $\left(90-170^{\circ}\right)$ coefficients at the three wavelengths. Nephelometer measurements could produce minor errors due to Rayleigh scattering of dry air and $\mathrm{CO}_{2}$ (Anderson et al., 1996; Anderson and Ogren, 1998) and care was taken to calibrate periodically using $\mathrm{CO}_{2}$ and air as high span and low span gases, respectively. The air inlet is taken from the ambient air at a height of about $30 \mathrm{~m}$ from the ground level and the instrument is housed in a room on the terrace of Physics Department building in JVD College of Science \& Technology, Andhra University. Care was taken to keep the length of the inlet pipe to less than $3 \mathrm{~m}$ to avoid aerosol loss by accumulation in the pipe. The instrument is operated with flow rate of $20 \mathrm{~L} \mathrm{~m}^{-1}$ and with a time resolution of $1 \mathrm{~min}$. Since it is not possible to integrate the scattering in the angular region of $0-180^{\circ}$, the measured data were corrected for angular truncation error and for the non ideality in the geometry of the instrument following the method suggested by Anderson and Ogren (1998). They analyzed the Nephelometer measurements as a function of particle size and reported that particles greater than $4 \mu \mathrm{m}$ do not contribute to the measurements since the bigger size particles scatter more in the near forward direction. The total scattering coefficient $\left(\sigma_{\mathrm{sp}}\right)$ and back scatter coefficient $\left(\sigma_{\mathrm{bsp}}\right)$ are calculated from nephelometer measured values $\left(\sigma_{\mathrm{sp}}(\mathrm{Neph})\right.$ and $\sigma_{\mathrm{bsp}}(\mathrm{Neph})$, respectively) as:

$\sigma_{\mathrm{sp}}=\sigma_{\mathrm{sp}}(\mathrm{Neph}) \cdot C$

and

$\sigma_{\mathrm{bsp}}=\sigma_{\mathrm{bsp}}(\mathrm{Neph}) \cdot C_{\mathrm{b}} \ldots \ldots$

where the correction factors $C$ and $C_{\mathrm{b}}$ are taken from Table 4 of Anderson and Ogren (1998).

While sampling the ambient air for the measurement of scattering coefficient, the effect of atmospheric humidity on hygroscopic aerosol particle growth should be considered and therefore measurements have to be normalized for a standard atmospheric humidity, which is taken as $30 \%$ in the present study. The method suggested by Ramachandran and Rajesh (2008) was followed in estimating the hygroscopic scaling factor (SF) expressed as the ratio of scattering coefficient at ambient Relative Humidity (RH) to the scattering coefficient at $30 \% \mathrm{RH}$. Scattering coefficients " $\sigma_{\mathrm{sp}}$ " at
450,550 , and $700 \mathrm{~nm}$ were calculated for $\mathrm{RH}$ varying from $30 \%$ to $80 \%$ using log normal distribution parameters from Hess et al. (1998) for maritime polluted aerosol model. This model represents a marine environment under the anthropogenic influence, which is appropriate for Visakhapatnam. The SF at $550 \mathrm{~nm}$ for maritime aerosol model are found to be $1.15(40 \%), 1.298(50 \%), 1.45(60 \%), 1.6(70 \%)$, and 1.82 $(80 \%)$. SF estimated in this study are in agreement with the mean values obtained by Hegg et al. (1996) and Charlson et al. (1984).

Though losses within the Nephelometer instrument for super micron particles could be slightly higher (in the range 5$10 \%$, see Anderson and Ogren, 1998), they are relatively insignificant since the present measurements relate to a coastal urban location, where the sub-micron particles dominate as seen from the aerosol near surface mass size distribution. The uncertainties associated with aerosol inlets, tubing and losses within the instrument are reported to be insignificant for sub micron particles (Clarke et al., 2002; Ramachandran and Rajesh, 2008). The overall uncertainty after due consideration of the above parameters and incorporating the relevant corrections is estimated to be about $10-15 \%$ in the estimation of the scattering coefficients.

A seven channel Aethalometer Model NO: AE-47 developed by Magee Scientific Company is operated with a time resolution of $5 \mathrm{~min}$ and a standard mass flow rate of 1.9 liters per minute. These data are used to evaluate the absorption coefficients at each of the seven wavelengths, viz. 370, 470, 520, 590, 660, 880, and $970 \mathrm{~nm}$. Arnott el al. (2005) discussed in detail the intrinsic problems associated with the filter based optical measurements of Black Carbon (BC) and Corrigan et al. (2006) recalculated the correction parameters for the realistic and ambient conditions based on the onedimensional two stream radiative transfer correction method described by Arnott et al. (2005). Using the values of Table 2 in Corrigan et al. (2006), the absorption coefficients $\sigma_{\text {abs }}$ were estimated and the maximum uncertainty in the estimation was calculated to be $20 \%$. Absorption coefficients at the Nephelometer wavelengths $(450,550,700 \mathrm{~nm})$ are calculated from the spectral dependency of $\sigma_{\text {abs }}$.

From the simultaneous data on absorption and scattering coefficients, SSA is calculated as follows:

$\omega=\sigma_{\mathrm{sp}} / \sigma_{\mathrm{ext}} \ldots$

where $\sigma_{\text {ext }}$ is the extinction coefficient, which is the sum of absorption and scattering coefficients. The back scatter ratio " $b$ " and asymmetry parameter " $g$ " are calculated from the Nephelometer scattering coefficients (Wiscombe and Grams, 1976; Andrews et al., 2006; Ramachandran and Rajesh, 2008):

$b=\sigma_{\mathrm{bsp}} / \sigma_{\mathrm{sp}} \ldots \ldots \ldots$

$g=-7.143889 \cdot b^{3}+7.464439 \cdot b^{2}-3.96356 \cdot b+0.9893 \ldots .(5)$ 

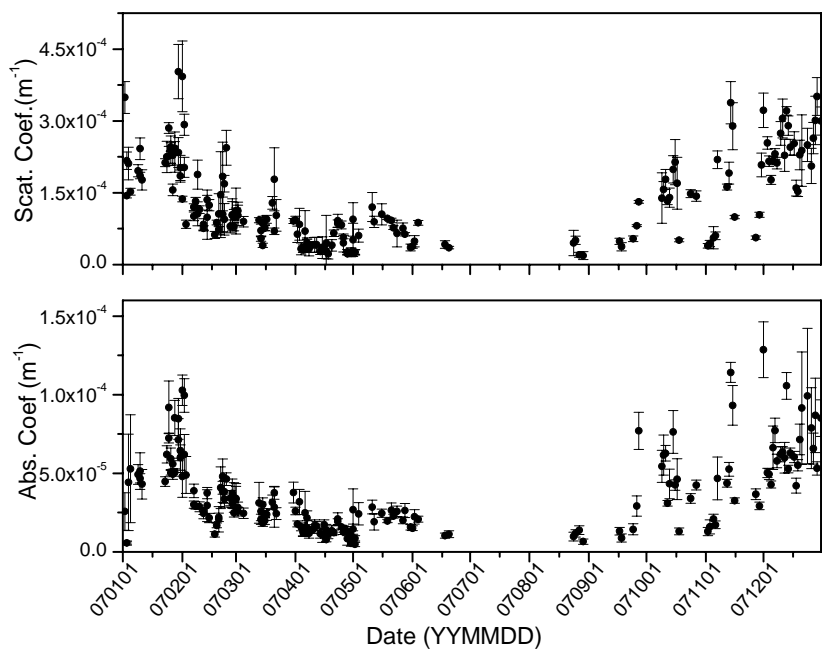

Fig. 1. Temporal variation of scattering coefficients (top panel) and absorption coefficients (bottom panel) at $550 \mathrm{~nm}$ obtained from in situ measurements.

The above equation connecting " $b$ " and " $g$ " was one of the methods suggested by Andrews et al. (2006) based on the plot of Wiscombe and Grams (1976) following HenyeyGreenstein approximation for " $g$ ".

Co-located measurements on aerosol physical and optical properties were used to interpret the observed variations in the SSA. The measurements included: (i) aerosol optical depths (AOD) at 5 wavelengths centered about 380, 440, 500, 675, and $870 \mathrm{~nm}$ using a Microtops II Sun Photometer (Solar Light Co, USA), with a Global Positioning System (GPS) receiver attached to the Photometer to provide information on the location, altitude, and pressure; and (ii) near surface aerosol mass concentrations using a ten channel Quartz Crystal Microbalance (QCM) Impactor (California Measurements Inc., USA), whose $50 \%$ aerodynamic cutoff diameters are $25,12.5,6.4,3.2,1.6,0.8,0.4,0.2,0.1$, and $0.05 \mu \mathrm{m}$, respectively, with an air inlet at a flow rate of 0.24 liters per minute and sampled for duration of $300 \mathrm{~s}$.

Regarding the error estimates, typical combined error in AOD measurement using the Microtops II sun photometer as described by Porter et al. (2001) and Ichoku et al. (2002) is in the range 0.009 to 0.0119 (around $1 \%$ ) at different wavelengths and the absolute uncertainty in the AOD measurement is \pm 0.03 . An error of \pm 0.03 is an error of $\pm 6 \%$ for a mean optical depth of 0.5 . It is probably more important to note that the absolute error is smaller than the measured standard deviation of the optical depth shown in Fig. 6. The QCM system estimates the mass concentration in each size bin by measuring the change in the frequency between a reference crystal and sensing crystal. The difference in frequency is proportional to the mass of the aerosols deposited on the sensing crystal and therefore the stability of the crystal oscillator during the sampling time is important. Ran- dom checks are made periodically with ambient air bypassed from the inlet valve. Considering the frequency shifts into aerosol mass, estimates below $10 \mu \mathrm{g} \mathrm{m}^{-3}$ are generally more uncertain (by $\sim 15-20 \%$ ), which works out to be $1 \mu \mathrm{g} \mathrm{m} \mathrm{m}^{-3}$ while errors are quite small for higher values of mass concentration. Another important consideration is the affinity of quartz crystal substrate to moisture above $75 \% \mathrm{RH}$, as QCM requires rather stable RH levels during sampling period. Therefore, the QCM and Nephelometer measurements were restricted to less than $75 \%$ ambient RH levels and the estimated error was in the range of less than $10 \%$ following the error budget made by Pillai and Moorthy (2001).

\section{Results and discussion}

\subsection{Aerosol absorption and scattering coefficients}

Figure 1 shows the scattering coefficients (top panel) and absorption (bottom panel) at $550 \mathrm{~nm}$ derived from the in situ measurements using the 3 colour Nephelometer and 7 channel Aethalometer. A systematic seasonal variation in both the parameters is seen, with winter maximum and monsoon minimum. Due to cloudy skies and intermittent rains, the data during monsoon months is not very extensive since we do not operate the nephelometer and aethalometer when the humidity is high to avoid deposition in the air inlet tubing. However, we have data for a few representative days (28) of this season also to evaluate the seasonal characteristics. The observed winter maximum is assumed to be due to the boundary layer subsidence and the resultant confinement of aerosols. This type of boundary layer dynamic due to surface temperature variations could be the reason for the large scatter in the absorption and scattering coefficients observed in winter. Secondly, at the station, the air mass pathway to the observing site during winter is from a NE direction, bringing mostly the continental air and leading to an enhanced anthropogenic component (Niranjan et al., 2004). Further, it should be noted that the BC mass concentration was consistently $10 \%$ of the total fine mode fraction in all the seasons, viz. summer (March to May), monsoon (June to August), post monsoon (September and October), and winter (November to February), as indicated by the near surface mass size distribution measurements using a QCM, which indicates that BC is well mixed in the ambient fine mode aerosol (Sreekanth et al., 2007) throughout the year. Niranjan et al. (2006), using simultaneous measurements from an aethalometer, a QCM, and a Micro Pulse Lidar at Kharagpur (a station in the Indo-Gangetic plains), reported that a 40-50\% compression in the boundary layer resulted in a proportionate increase in the near surface mass concentration of the composite aerosol. During summer, dispersion of aerosols is high owing to the large ventilation coefficient which is a product of the mixing height and local horizontal wind speed, and therefore the 


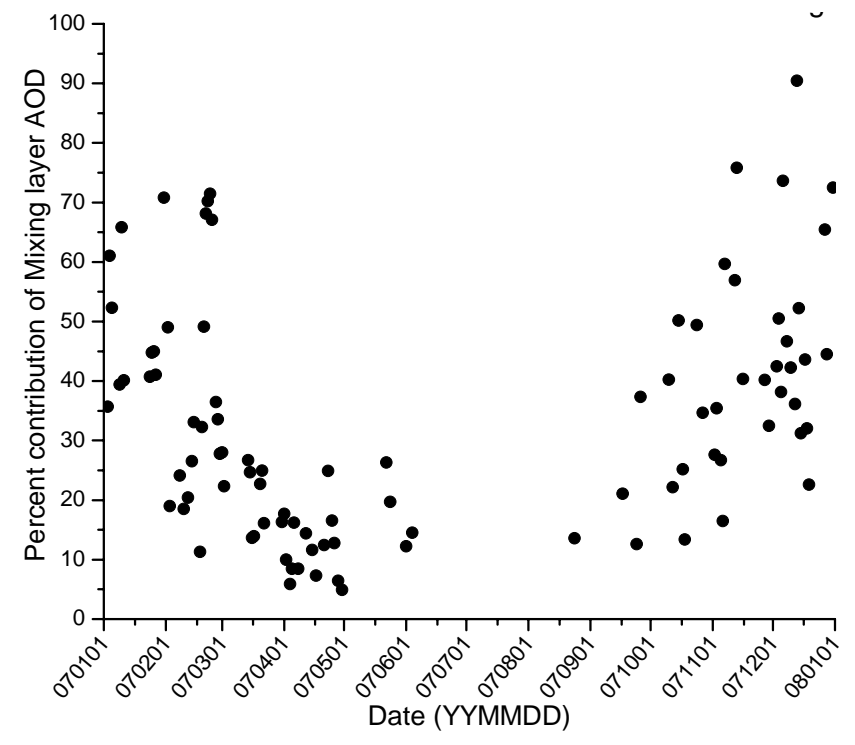

Fig. 2. Percent contribution of mixing layer aerosol to column optical depth.

surface concentrations are relatively low compared to winter months.

Aerosol composition is important mainly in determining the scattering and absorbing characteristics of aerosol. During summer months, the prevailing wind blows from south/southwest, bringing in the mixture of marine and urban aerosol from the industrial area located SW of the observing site (Niranjan et al., 1997, 2004). Earlier observations on the aerosol chemical composition at Visakhapatnam during the summer and monsoon period (May to August) indicated an abundance of sea salt aerosol, which alone contributed to about $53 \%$ of water soluble ionic species (Madhavan et al., 2008). Secondly, the negative second order Angstrom wavelength exponent $\left(\alpha^{\prime}\right)$ indicated a dominance of aerosol fine mode fraction which undergo a transformation process resulting in the increase of coarse mode aerosols during the pre-rainy season, as observed by the positive curvature of $\alpha^{\prime}$ during this period (Schuster et al., 2006). It should also be noted that $37 \%$ contribution to the mass fraction of the coarse mode aerosol was potentially due to the sea salt aerosol. Further, the higher production of the nucleation mode aerosol by the gas-to-particle conversion from the industrial emission located southwest of the observing site also contributed to the generation of the positive curvature.

The mixing layer contribution to column AOD is calculated as the product of mixing layer height and the surface extinction coefficient $\left(\sigma_{\mathrm{ext}}\right)$. Atmospheric mixed layer height is derived from the Micro Pulse LIDAR data. Mixed layer is defined as that region directly influenced by the earth's surface. The layer height is considered as the base of the transition zone, i.e. the interface between the mixed layer and the free troposphere (Flamant et al., 1997), a definition as-

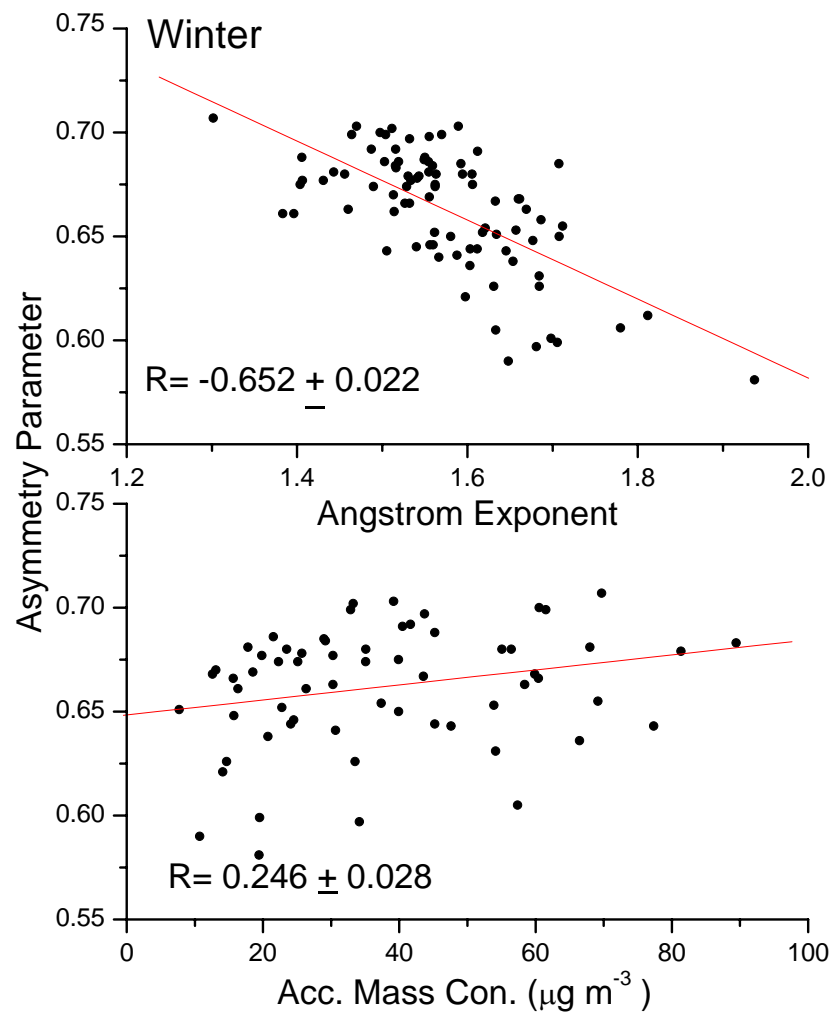

Fig. 3. Variation of asymmetry parameter $(g)$ with accumulation mode concentration (in $\mu \mathrm{g} \mathrm{m}^{-3}$ ) and Angstrom exponent $(\alpha)$ during winter season.

sociated with the first derivative of temperature approach. It is considered that the potential temperature nearly remains steady within the boundary layer, whereas the top of the boundary layer is marked by sudden change in the lapse rate. We have evaluated the boundary layer height using the second derivative approach in the aerosol back scatter intensity, wherein the minimum point of the 9 point smoothed second derivative profile with $30 \mathrm{~m}$ resolution is considered as the top of the boundary layer (Chen et al., 2001; Niranjan et al., 2006). Interestingly, the percentage contribution of AOD up to mixing layer height as shown in Fig. 2 is below $35 \%$ in summer and monsoon, while it is well above $35 \%$ in the winter. This is likely a consequence of efficient aerosol ventilation to higher altitudes during the summer and monsoon months due to convective activity. Because of the confinement of aerosol within the boundary layer during winter months, the column AOD is more weighted by the mixing layer contribution to the extent of almost $100 \%$ in some cases.

Another important parameter of interest for single valued representation of angular scattering in radiative forcing estimation is the asymmetry parameter " $g$ ". Andrews et al. (2006) investigated the range of values of " $g$ " and how it effects the calculations of forcing. Calculation of radiative forcing over a range of observed asymmetry parameters 


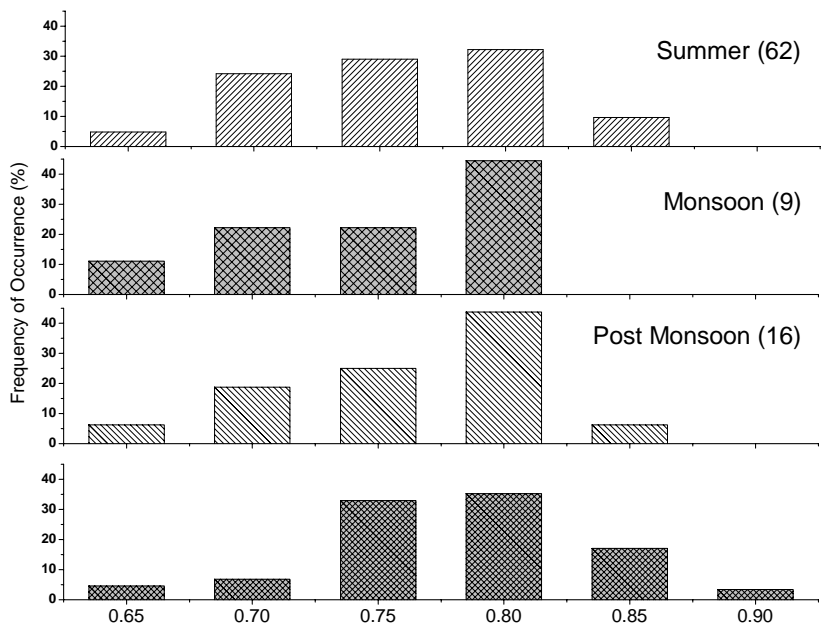

Fig. 4. Frequency of occurrence of SSA (at $550 \mathrm{~nm}$ ) during summer, monsoon, post-monsoon, and winter seasons (2007). Parenthetical numbers represent number of observations for each season.

showed that a $10 \%$ decrease in " $g$ " corresponds to a $19 \%$ reduction in radiative forcing at the top of the atmosphere and a $13 \%$ reduction at the surface. With a view to see the range of " $g$ " values representative for the location under study, we have evaluated the value of " $g$ " for winter from the scattering coefficient " $b$ " in relation (5) (Wiscombe and Grams, 1976; Ramachandran and Rajesh, 2008) and presented the same in Fig. 3. Generally, the asymmetry parameter varied in the range $0.65 \pm 0.1$ for this location. When viewed as a function of surface aerosol mass concentration in the accumulation mode and the Angstrom exponent " $\alpha$ ", $g$ shows a small positive correlation with accumulation mode aerosol as shown in Fig. 3. Investigation of the factors controlling the value of the asymmetry parameter suggested that the aerosol size distribution, specifically the accumulation mode (particle diameter in the range $0.1 \mu \mathrm{m}$ to $1.0 \mu \mathrm{m}$ ), was most important to measure, and the present results indicated a slight positive correlation between the asymmetry parameter and the accumulation mode aerosol. In contrast, " $g$ " showed a significant negative correlation with the Angstrom size index " $\alpha$ " during winter months, while it was not so systematic during the summer and monsoon months and hence the figure for these months was not shown. This could be because of the confinement of aerosols within the boundary layer, therefore showing a strong dependence on the particle size distribution depending on the local sources, which was not so during the summer months due to the possibility of aerosol ventilation and non local aerosol transport.

\subsection{Seasonal features of Aerosol Single Scattering Albedo}

Aerosol SSA, derived by taking the ratio of scattering to total extinction from the simultaneous measurements of scattering and absorption coefficients, varied between 0.65 and 0.9 over Visakhapatnam during different seasons (Fig. 4). Actually, 0.8 appears to be the most probable value in all the seasons. The monsoon and post monsoon seasons show the largest peak at 0.8 relative to other values of SSA. The numbers in the parentheses of the season legend indicate the number of observations. The mean value of SSA was $0.78 \pm 0.05$ during winter, $0.75 \pm 0.04$ during summer, $0.75 \pm 0.06$ during monsoon, and $0.76 \pm 0.05$ during post monsoon season.

Since aerosol SSA depends on the absorbing part of the extinction as well as on the aerosol size distribution, and since the absorbing aerosols are mostly in the sub-micron region, we have plotted in Fig. 5 the size segregated mean aerosol mass in the nucleation (aerodynamic diameter $<0.1 \mu \mathrm{m}$ ), accumulation (aerodynamic diameter in the range $0.1 \mu \mathrm{m}$ to $1.0 \mu \mathrm{m}$ ), and coarse (aerodynamic diameter $>1.0 \mu \mathrm{m}$ ) modes measured using a QCM system along with the mean BC mass concentration measured using a 7 channel aethalometer as a function of the observed SSA. The SSA measurements were sorted into bins of 0.05 ranges around the bin centre, and the mean of the near surface mass and $\mathrm{BC}$ concentrations were evaluated for the observations included in the respective bin. For example, at SSA 0.7, observations of all days showing SSA in the range 0.675 to 0.725 were aggregated and the means were evaluated for those points. It should be noted that during the post monsoon and winter months a systematic decrease in the SSA was observed as the surface BC mass concentration increased. In winter, when the SSA was 0.65 the surface BC mass concentration was $9.35 \mu \mathrm{g} \mathrm{m}^{-3}$, and when the SSA increased to 0.90 the surface BC was $1.56 \mu \mathrm{g} \mathrm{m}^{-3}$, clearly indicating the control of the absorbing aerosol on the SSA. Similarly, when SSA was 0.65 during post monsoon season the surface $\mathrm{BC}$ was $10.95 \mu \mathrm{g} \mathrm{m}^{-3}$, while it was $5.77 \mu \mathrm{g} \mathrm{m}^{-3}$ when the SSA was 0.85 . In Fig. 5, the percent $\mathrm{BC}$ mass fraction in fine mod aerosol was also shown by a dark bar, which clearly indicates the systematic dependence of SSA on absorbing aerosol in winter and post monsoon seasons. During summer months such systematic variation in the absorbing aerosol was not seen. However, when the SSA increased to 0.85 , the integrated near surface aerosol mass in the nucleation and accumulation mode together almost doubled, indicating the dominance of the submicron particles. During summer months the wind is mostly from the south/southwest, bringing in the marine aerosol as well to the observing location. This might have resulted in an abundance of sea salt aerosol, which could have increased the scattering coefficient and hence the SSA might have increased, though there was sufficient amount of BC aerosol present as indicated by the BC mass concentration. Secondly, during summer the gas phase industrial products from the industrial area located southwest of the observing site interact with the marine airmass, which favours the gas-to-particle conversion process and hence nucleation and accumulation aerosol production increases thereby, enhancing the scattering. At Visakhapatnam, which is a coastal station, the sea 


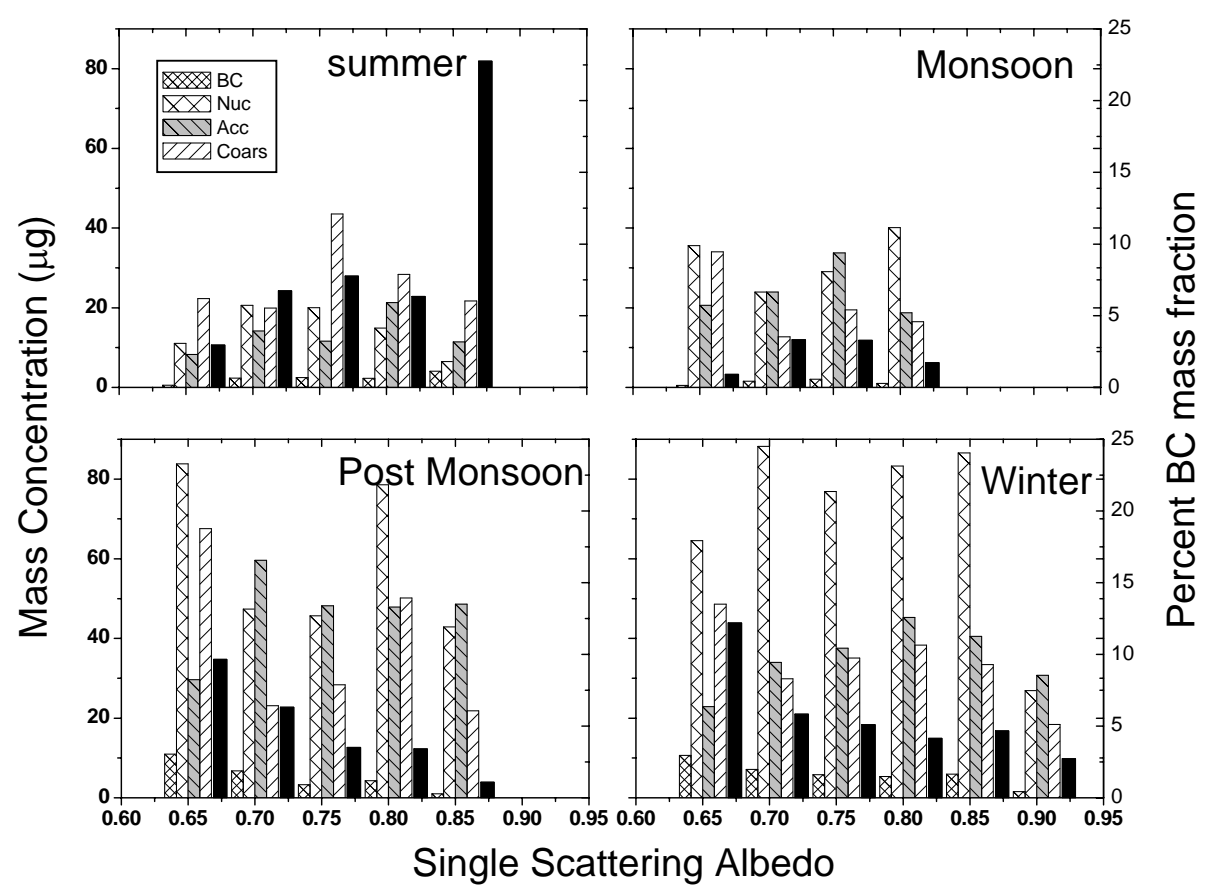

Fig. 5. Surface level size segregated (nucleation, accumulation, and coarse modes) mean aerosol mass concentrations (in $\mu \mathrm{g} \mathrm{m}^{-3}$ ) measured using QCM system along with simultaneous mean BC mass concentrations (in $\mu \mathrm{g} \mathrm{m}^{-3}$ ) using the 7 channel Aethalometer as a function of the observed SSA (at $550 \mathrm{~nm}$ ) during summer, monsoon, post-monsoon, and winter seasons. Also shown is the percent BC mass fraction in fine mode aerosol (dark bar).

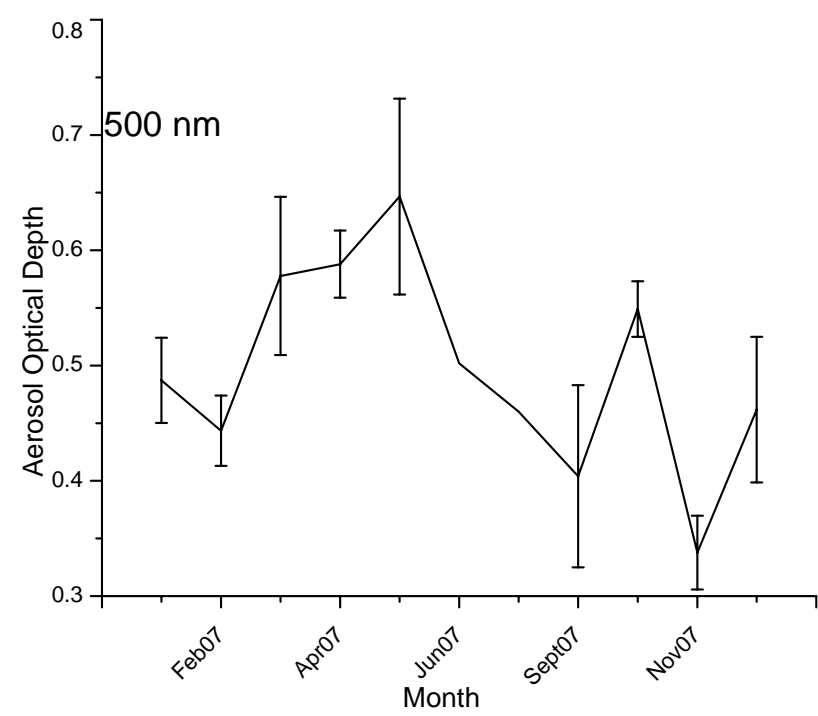

Fig. 6. Monthly variation of mean AOD (at $500 \mathrm{~nm}$ ) along with standard deviation measured using MICROTOPS II Sun photometer.

breeze onset occurs around 09:00 IST and is associated with the higher humidity, which favours the nucleation and subsequent growth of the aerosol particles.
The state of aerosol mixture such as internal or external is also important to determine the SSA. Ohta et al. (1996) calculated the SSA based on their observation in the range from 0.96 to 0.9 for an external mixture and in the range from 0.85 to 0.93 for an internal mixture of elemental carbon and sulfate aerosol for free atmosphere conditions. Due to the presence of the abundance of both the BC as well as the sulfate aerosol owing to the coastal industrial nature of the observing location, it is expected that the state of aerosol over the eastern part of India could be an internal mixture since the inferred SSA falls around 0.8 most of times.

Figure 6 shows the aerosol optical depth (AOD) at $500 \mathrm{~nm}$ measured using a Microtops II sun Photometer. It should be noted that the AOD is high during summer months and minimum during the monsoon months. Since SSA is an intrinsic parameter, it does not totally dependent on aerosol optical depth since column optical depth also reflects the overall abundance of aerosols. It depends only on the ratio of scattering to total extinction. However, it is important to know whether the surface measured SSA reflects the aerosol scattering characteristics in the complete vertical column, as the aerosol composition may not be uniform throughout the vertical column and the SSA evaluated from surface measurements may not at all times represent the column integrated features. It is known that the spectral variation of Angstrom exponent $(\alpha)$ is strongly dependent on the atmospheric turbidity $(\beta)$ and aerosol type (Eck et al., 1999; 


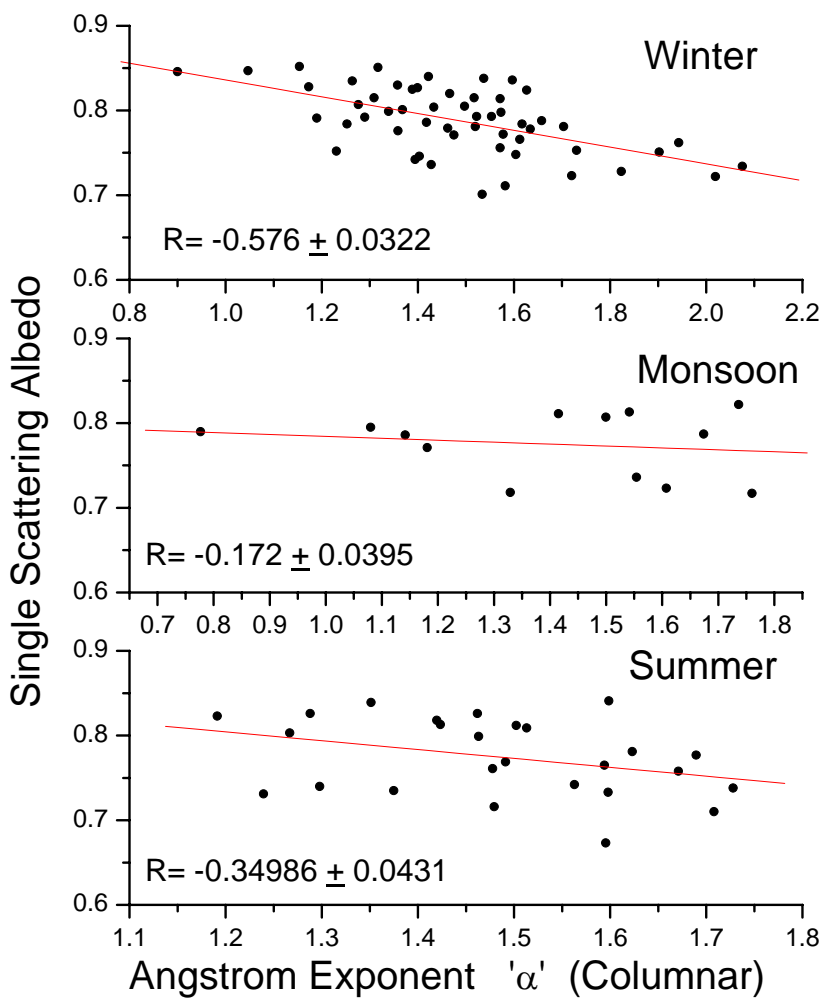

Fig. 7. Scatter plot of SSA (at $550 \mathrm{~nm}$ ) against column Angstrom exponent $(\alpha)$ during winter, monsoon, and summer months. Numbers within panels define correlation coefficents.

Cachorro et al., 2001; Reid et al., 1999). To assess this, we have derived the column Angstrom size index " $\alpha$ " by estimating the Angstrom wavelength exponent " $\alpha$ " in the relation $\tau_{\lambda}=\beta \lambda^{-\alpha}$ (Angstrom, 1964; Eck et al., 1999), where $\tau_{\lambda}$ are the spectral AOD, $\lambda$ is the wavelength in $\mu \mathrm{m}$ and $\beta$ the turbidity coefficient (equivalent to AOD at $1 \mu \mathrm{m}$ ), presenting it against the SSA for 2007 winter, monsoon, and summer seasons in Fig. 7. Although $\alpha$ and $\beta$ are assumed independent of the wavelength, it is well known that both parameters depend on wavelength. Both $\alpha$ and $\beta$ have been estimated for each of the observed AOD spectra by deriving a linear least squares fit to Angstrom relation in a log-log scale and are averaged daily. In general, the fits were very good with a correlation exceeding 0.95 .

Simultaneous measurements of AOD and SSA are limited to the data pertaining to clear sky conditions as the AODs could be evaluated with least error only during these days. It should be noted that during winter, the SSA decreased as the abundance of small particle concentration increased as reflected by the increase in $\alpha$. These two parameters are derived from two independent experiments, one relating to the surface measurements and the other reflecting the column integrated features. During winter months due to the compression of boundary layer and consequent inhibition of aerosol ventilation, the aerosols are confined to the near sur- face region, the surface measured SSA more or less indicating the characteristics of the complete column as reflected by the good correlation observed during the winter months (the numbers in each panel of Fig. 7 are the correlation coefficients). The goof winter correlation in Fig. 7 also implies that most of the absorption is due to small particles in winter months, while the correlation was poor in summer and monsoon months. However, due to the convective activity during summer months, aerosol vertical transport is significant and as a consequence, the possibility for non local transport of aerosol in the upper altitude regions is high, which might have resulted in the relatively poor correlation between column $\alpha$ and surface SSA. Niranjan et al. (2007) indicated that during summer months elevated aerosol layers are more probable over the observing site, whose origin was traced to be from Arabia in $60 \%$ of the cases with significant fraction of dust aerosol, while it is from peninsular India during the rest of the event. This observation probably indicates that the surface measured SSA has to be used with caution during summer months for evaluating the aerosol radiative forcing representative of vertical column, while it is reasonably valid that surface measured SSA could be extended to column during winter months. During monsoon months the data are limited, which, as previously mentioned, show a poor correlation between surface SSA and column $\alpha$.

\subsection{Day to day variability in SSA}

The above study reflects the mean variability in SSA against various parameters. But there are certain days when the SSA does not show variability in line with the variations in BC and near surface mass concentration. Therefore, we have selected two days from each season which represent typical high and low SSA and examined whether these days fall in the mean characteristics category. Figure 8 shows the variation of SSA (top panel), surface aerosol mass concentration in the three modes along with the BC mass (middle panel), and the aerosol optical depth spectra (bottom panel) for those selected days. During winter, on 14 November 2007 the SSA was 0.75 with a mean surface BC mass concentration of $14.02 \mu \mathrm{g} \mathrm{m}^{-3}$, while on 15 February 2007 the SSA was 0.85 when the mean surface $\mathrm{BC}$ mass concentration decreased to $2.7 \mu \mathrm{g} \mathrm{m}^{-3}$, falling in line with the general behaviour of decrease in absorption from BC leading to an increase in SSA. However, the aerosol size index " $\alpha$ " for the high SSA case from the surface and column measurements is 1.4 and 1.3 (15 February 2007), respectively, while it is 1.38 and 1.75 (14 November 2007), respectively, for the low SSA case. This indicates that on the day with high SSA (15 February 2007), there is significant aerosol ventilation and uniform mixing of aerosol properties in the column. However, on the day with low SSA the surface $\alpha$ was marginally low, indicating the relative increase of coarse mode aerosols at the surface compared to the dominance of fine mode aerosols in the column. The surface aerosol mass size distribution on the day 

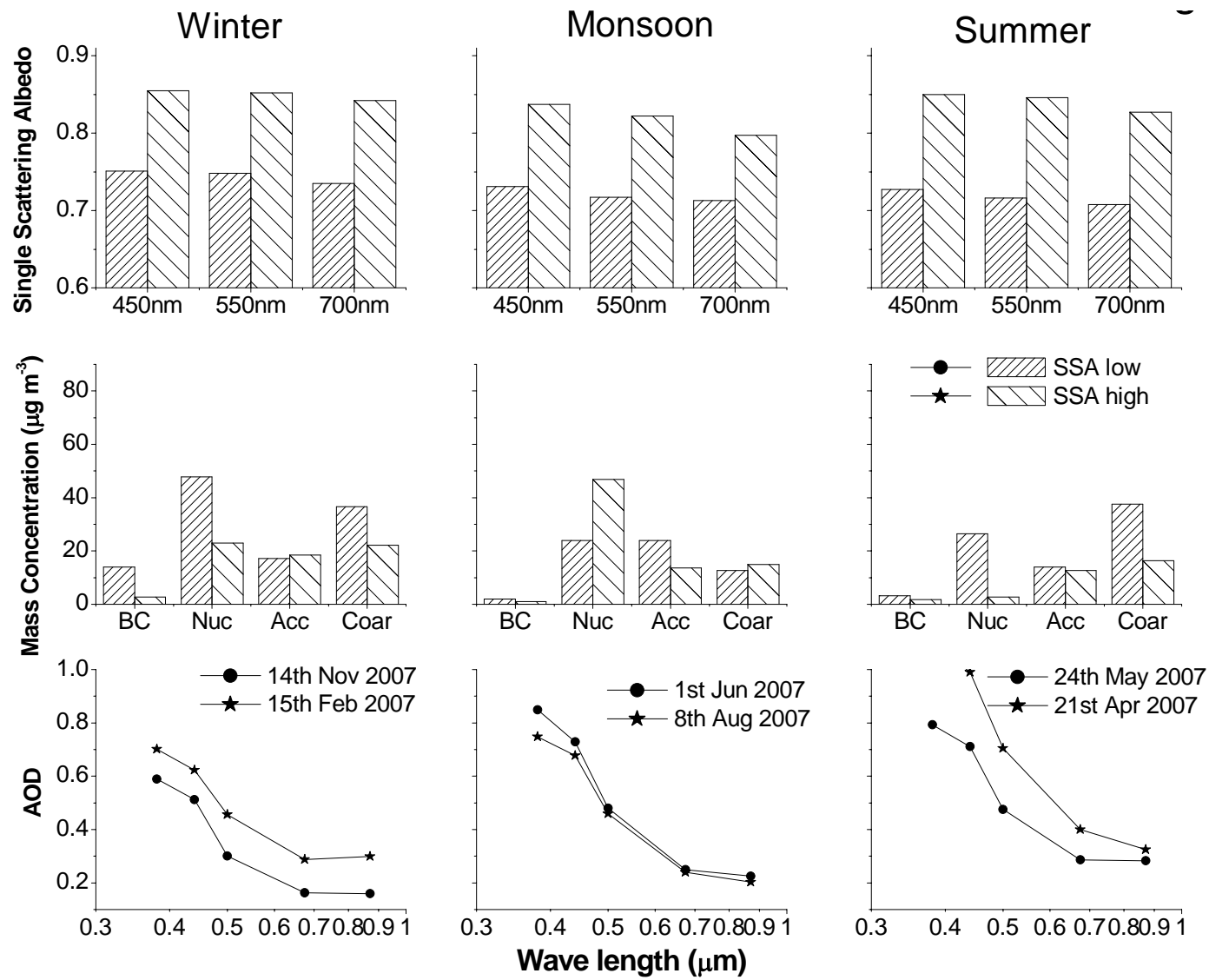

Fig. 8. Variation of SSA (at $550 \mathrm{~nm}$, top panel), surface aerosol mass concentrations (in $\mu \mathrm{g} \mathrm{m}^{-3}$ ) in the three modes along with the BC mass concentration (in $\mu \mathrm{g} \mathrm{m}^{-3}$ middle panel), and spectral AOD for the selected days which do not fall in the mean pattern (bottom panel).

with low SSA also indicates a marginal increase in percent coarse mode fraction (43\%) compared to the day with low SSA (36\%), indicating an increase in scattering that might have partially contributed to an increase in SSA.

For the monsoon season, for high SSA of 0.84 the BC mass was $1.98 \mu \mathrm{g} \mathrm{m}^{-3}$, while for low SSA of 0.73 the BC mass was $0.88 \mu \mathrm{g} \mathrm{m}^{-3}$. The column and surface $\alpha$ on the high SSA day were 1.73 and 1.53 , respectively, showing a well mixed condition with not much of a change in size distribution throughout the column. In the case of low SSA the column and surface $\alpha$ were 1.76 and 1.19 , respectively, which indicate a possible increase in the coarse mode aerosol fraction at the surface level. However, no such increase in the surface coarse mode aerosol fraction was observed in the aerosol size segregated mass size distribution shown in the middle panel. If we look at the column optical depths, an increase in the aerosol optical depth at shorter wavelengths was observed that led to an increase in the derived $\alpha$ from the column spectral optical depths. This indicates a decoupling of the surface and column features and the contribution of submicron aerosol from higher altitudes to the increase in column $\alpha$.
During summer, both the days of high and low SSA recorded a surface BC mass concentration of 3.16 and $1.75 \mu \mathrm{g} \mathrm{m}^{-3}$, respectively, and the aerosol optical depth spectra also looked alike. The surface and column $\alpha$ values were 1.45 and 1.59 , respectively, for high SSA case and were 1.32 and 1.38 respectively for low SSA case. A proportionate increase in the coarse mode aerosol mass concentration was recorded on the high SSA case compared to the day with low SSA, leading to an increase in scattering since the scattering cross section is more for larger particles. These typical cases of summer indicate a well mixed aerosol with surface and column features absolutely matching. In these cases no upper air contribution from non local aerosol in the form of elevated layers is expected, though they are found to be more probable in summer (Niranjan et al., 2007).

\subsection{Typical diurnal variation in SSA}

In addition to seasonal and day to day variability it is important to investigate whether the average scattering and absorbing coefficients evaluated reflect the daily mean or not. Hence, we have investigated the diurnal pattern in these coefficients and SSA on a few typical summer and winter 


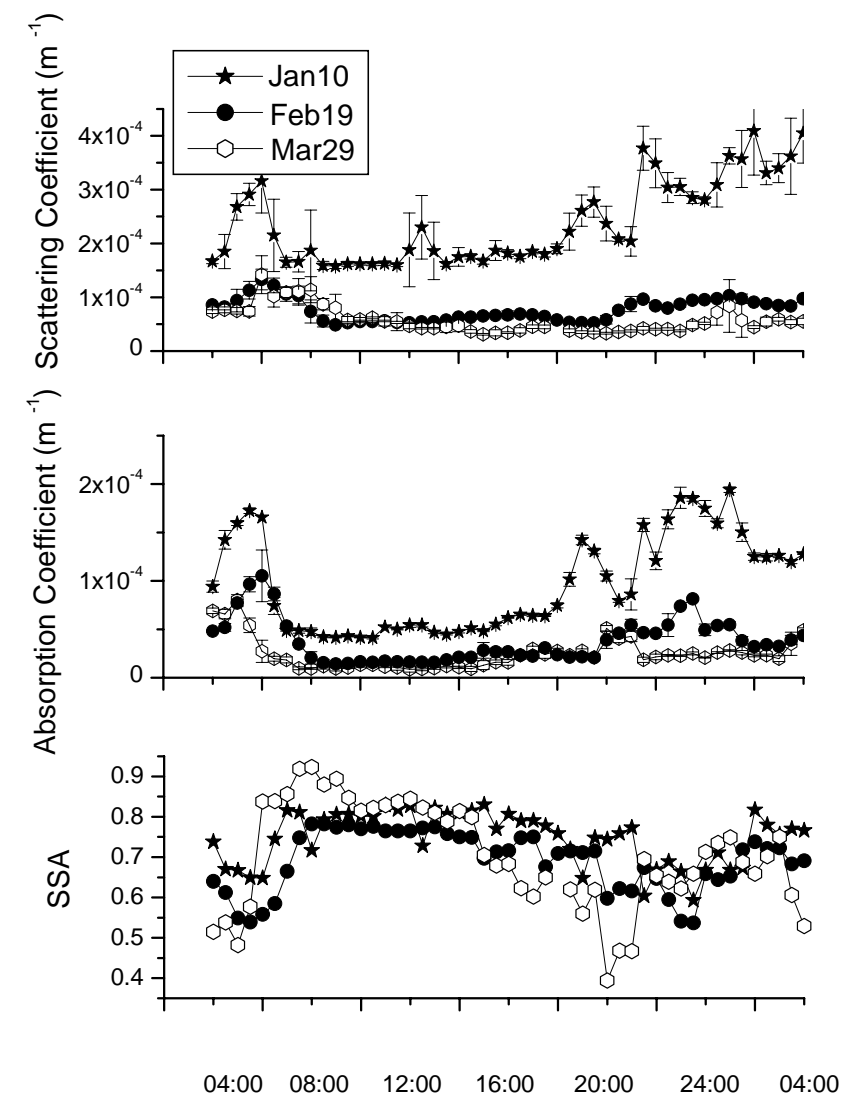

Fig. 9. Diurnal variation of scattering coefficients (top panel) and absorption coefficients (middle panel) and SSA (bottom panel) at $550 \mathrm{~nm}$ for typical winter days (10 January and 19 February 2007) and one typical summer day (29 March 2007).

days. We could not obtain any diurnal variations during monsoon months due to unfavourable conditions with intermittent rains. Figure 9 shows the diurnal variation of scattering coefficients at $550 \mathrm{~nm}$ (top panel) and absorption coefficient (middle panel) for two typical winter days (10 January and 19 February 2007) and a typical summer day (29 March 2007). It should be noted that winter days are characterized by a typical morning increase in the absorption and scattering coefficients due to the subsidence of the atmospheric boundary layer and consequent confinement of aerosols. As day progresses, surface heating and consequent build up of convective activity and subsequent aerosol ventilation causes the coefficients to decrease due to the decrease in aerosol population at the surface level. However, during summer this type of confinement of aerosol during morning hours does not take place.

One important point to note is that these two coefficients do not show a significant variation during 10:00-17:00 IST, the time very important for radiative transfer applications since it is the time for maximum insolation. One of the important features is the significant increase in SSA during summer daytime hours between 08:00 to 12:00 h, which re-

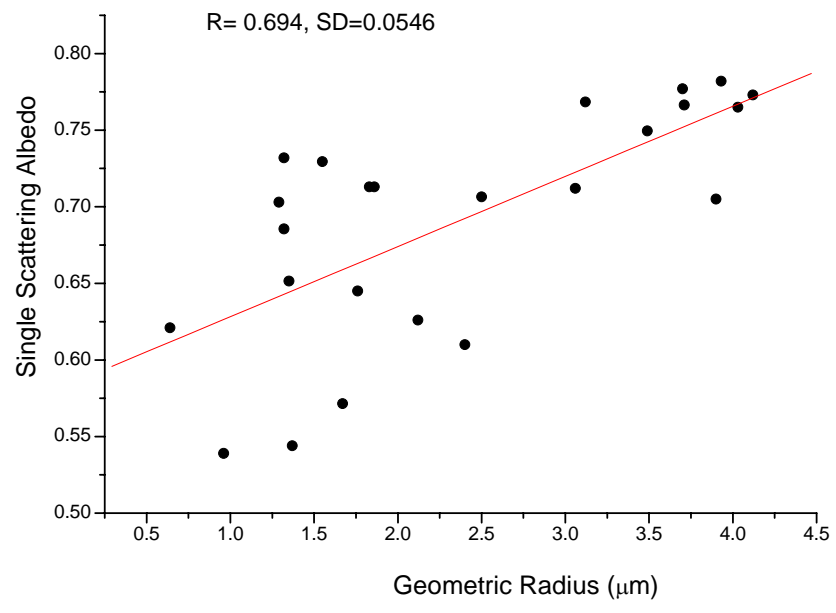

Fig. 10. Scatter plot showing the variation of SSA (at $550 \mathrm{~nm}$ ) with geometric mean radius (in $\mathrm{mm}$ ) evaluated from surface aerosol size dsitribution for a typical winter day (19 February 2007).

flects the aerosol ventilation and consequent decrease in absorbing aerosol.

Moorthy et al. (2003) have suggested a method for evaluating the geometric mean radius from the measurement of size segregated aerosol mass concentration by converting it to corresponding volume and using the aerodynamic particle diameter of different cut-off stages of the QCM system and the actual particle density. It is interesting to note the variation of SSA as a function of geometric mean radius evaluated from surface aerosol size distributions shown for a typical winter day in Fig. 10. It may be seen that the SSA increases as the geometric mean radius of the aerosol increases with a very good correlation.

From the measurement of aerosol optical properties during AREBeijing 2006, Garland et al. (2009) reported that pronounced diurnal cycles were observed in the aerosol intensive properties, with scattering and absorption coefficients having their maxima in the early morning and late evening hours as the nocturnal boundary layer formed, while the surface emission continued and then decreased during the day due to mixing with overlying residual layer. Gebhart et al. (2001) indicated from observations at different locations that there could be five broad categories of diurnal patterns which may be linked to aerosol sources and local meteorology. The aerosol is well mixed during summer and thus little diurnal variation is observed similar to that reported for seven sites, while that observed during winter resembles that reported for a few sites in the western US with early morning peak. These diurnal cycles are controlled by a combination of mixing due to the capping of aerosol ventilation by the nocturnal boundary layer during winter months and its breakup with the build up of convective activity during the post sunrise hours, together with the enhancement of aerosol population with the daybreak. Such confinement is 
not possible during summer nights which are quite hot and the aerosol is well mixed, meaning little diurnal variation is observed during the summer months.

\section{Summary}

A study on the aerosol SSA using scattering coefficient and absorption coefficient measurements using a three colour Nephelometer and a seven channel Aethalometer, respectively, revealed the following:

- The aerosol absorption and scattering coefficients show significant seasonal variation with winter high and summer low. Variation in scattering coefficient is relatively higher than absorption coefficient in summer.

- Mixed layer contribution to column AOD was below $35 \%$ during summer, while it reaches almost $100 \%$ in winter.

- The mean value of the asymmetry parameter " $g$ ", which is an index of angular scattering, was $0.65 \pm 0.1$.

- The SSA over Visakhapatnam varied in the range 0.65 to 0.9 with a most probable value around 0.8 . The mean value was found to be $0.76 \pm 0.13$ for Visakhapatnam.

- The variation of SSA is systematic either with the change in $\mathrm{BC}$ concentration or on the size distribution of the aerosols. In winter, monsoon, and post-monsoon months, the change in the SSA is following the change in $\mathrm{BC}$ mass concentration, whereas the change in the SSA during summer is more sensitive to aerosol size distribution.

- The variation of surface SSA with the columnar $\alpha$ is negative, indicating the dependence of SSA on columnar size distribution. The deviation of surface $\alpha$ from columnar $\alpha$ on some days during summer indicates contribution of higher altitude aerosol changes.

- Typical winter diurnal variation in aerosol intensive properties shows a morning peak, while during summer little diurnal variation is seen. During daytime hours no significant change in SSA is observed.

The results indicate that the SSA over this location shows a distinct temporal variation depending on the aerosol size distribution as well as on the aerosol dynamics. It is also likely that the aerosol properties may vary as a function of altitude, suggesting that typical SSA vertical profiling for different seasons, though difficult, may provide a handle on the applicability of the surface measurements in column integrated radiative transfer estimation.

Acknowledgements. This work is supported by the Indian Space Research Organization under ISRO-GBP Programme. One of the authors $(\mathrm{KN})$ thanks T. Shibata and the Nagoya University for a visiting facutly position during which time part of this work was done.

Topical Editor P. Drobinski thanks M. Garay and another anonymous referee for their help in evaluating this paper.

\section{References}

Anderson, T. L. and Ogren, J. A.: Determining aerosol radiative properties using the TSI 3563 Integrating Nephelometer, Aerosol Sci. Technol., 29, 57-59, 1998.

Anderson, T. L., Covert, D. S., Marshall, S. F., Laucks, M. L., Charlson, R. J., Waggoner, A. P., Ogren, J. A., Caldow, R., Holm, R. L., Quant, F. R., Sem, G. J., Wiedensohler, A., Ahlquist, N. A., and Bates, T. S.: Performance characteristics High-Sensitivity, 3wavelength Total Scatter/Back scatter Nephelometer, J. Atmos. Oceanic Technol., 13, 967-986, 1996.

Anderson, T. L., Covert, D. S., Wheeler, J. D., Harris, J. M., Perry, K. D., Trost, B. E., Jaffe, D. J., and Ogren, J. A.: Aerosol Backscatter Fraction and Single Scattering Albedo: Measured values and uncertainties at a coastal station in the pacific North West, J. Geophys. Res., 104(D21), 793-807, 1999.

Andrews, E., Sheridan, P. J., Fiebig, M., McComiskey, A., Ogren, J. A., Arnott, P., Covert, D., Elleman, R., Gasparini, R., Collins, D., Jonsson, H., Schmid, B., and Wang, J.: Comparison of methods for deriving aerosol asymmetry parameter, J. Geophys. Res., 111, D05S04, doi:10.1029/2004JD005734, 2006.

Angstrom, A.: The parameters of atmospheric turbidity, Tellus, 16 , 64-75, 1964

Arnott, W. P., Hamasha, K., Moosmuller, H., Sheridan, P. J., and Ogren, J. A.: Towards aerosol light-absorption measurements with a 7-wavelength aethalometer: Evaluation with a photoacoustic instrument and 3-wavelength nephelometer, Aerosols Sci. Technol., 39, 17-29, 2005.

Babu, S. S., Satheesh, S. K., and Krishna Moorthy, K.: Enhanced aerosol radiative forcing due to aerosol black carbon at an urban site in India, Geophys. Res. Lett., 29(18), 1880, doi:10.1029/2002GL015826, 2002.

Cachorro, V. E., Vergaz, R., and de Frutos, A. M.: A quantitative comparision of $\alpha$-Angstrom turbidity parameter retrieved in different spectral ranges based on spectraoradiomater solar radiation measurements, Atmos. Environ., 35, 5117-5124, 2001.

Charlson, R. J., Covert, D. S., and Larson, T. V.: Observation of the effect of relative humidity on light scattering by aerosols in Hygroscopic Aerosols, edited by: Rubuke, T. H. and Deepak, A., pp. 35-44, A. Deepak, Hampton, Va., 1984.

Chen, W., Kuze, H., Uchiyama, A., Suzuku, Y., and Takeuchi, N.: One year observation of urban mixed layer characterisitics at Tsukuba, Japan using a micro pulse lidar, Atmos. Environ., 35, 4273-4280, 2001.

Clarke, A. D., Howell, S., Quinn, P. K., Bates, T. S., Ogren, J. A., Andrews, E., Jefferson, A., and Massling, A.: INDOEX aerosol: A comparison and summary of chemical, microphysical, and optical properties observed from land, ship, and aircraft, J. Geophys. Res., 107(D19), 8033, doi:10.1029/2001JD000572, 2002.

Corrigan, C. E., Ramanathan, V., and Schauer, J. J.: Impact of monsoon transition on the physical and optical properties of aerosols, J. Geophys. Res., 111, D18208, doi:10.1029/2005JD006370, 2006. 
Dubovik, O., Holben, B., Eck, T., Smirnov, A., Kaufman, Y. J., King, M. D., Tanre, D., and Slutsker, I.: Variability of absorption and optical properties of Key aerosol types observe in worldwide locations, J. Atmos. Sci., 59, 590-608, 2002.

Eck, T. F., Holben, B. N., Reid, J. S., Dubovic, O., Smirnov, A., O'Neill, N. T., Slutsker, I., and Kinne, S.: Wavelength dependence of the optical depth of biomass burning, urban, and desert dust aerosols, J. Geophys. Res., 104(D24), 31333-31349, 1999.

Flamant, C., Pelon, J., Flamant, P., and Durand, P.: Lidar determination of the entrainment zone thickness at the top of the unstable marine boundary layer, Bound.-Lay. Meteorol., 83, 247-284, 1997.

Ganguly, D., Gadhavi, H., Jayaraman, A., Rajesh, T. A., and Misra, A.: Single scattering albedo of aerosols over the central India: Implications for the regional aerosol radiative forcing, Geophys. Res. Lett., 32(L1), 8803, doi:10.1029/2005GL023903, 2005.

Ganguly, D., Jayaraman, A., Rajesh, T. A., and Gadhavi, H.: Winter aerosol properties during foggy and nonfoggy days over urban centre Delhi and their implication for shortwave radiative forcing, J. Geophys. Res., 111, D15217, doi:10.1029/2005JD007029, 2006.

Garland, R. M., Schmid, O., Nowak, A., Achtert, P., Wiedensohler, A., Gunthe, S. S., Takegawa, N., Kita, K., Kondo, Y., Hu, M., Shao, M., Zeng, L. M., Zhu, T., Andreae, M. O., and Poschl, U.: Aerosol optical properties observed during Campaign of Air Quality Research in Beijing 2006 (CAREBeijing2006): Characteristic differences between the inflow and outflow of Beijing city air, J. Geophys. Res., 114, D00G04, doi:10.1029/2008JD010780, 2009.

Gebhart, K. A., Copeland, S., and Malm, W. C.: Diurnal and seasonal patterns in light scattering, extinction and relative humidity, Atmos. Environ., 35, 5177-5191, 2001.

Hansen, J., Sato, M., and Ruedy, R.: Radiative Forcing and Climate Response, J. Geophys. Res., 102, 6831-6864, 1997.

Haywood, J. N. and Shine, K. P.: The effect of anthropogenic Sulphate and soot aerosol on the clear sky planetary radiation budget, Geophys. Res. Lett., 22, 603-606, 1995.

Hegg, D. A., Covert, D. S., Rood, M. J., and Hobbs, P. V.: Measurements of aerosol optical properties in marine air, J. Geophys. Res., 101, 12893-12903, 1996.

Hess, M., Koepke, P., and Schult, I.: Optical properties of aerosols and clouds: The software package OPAC, Bull. Am. Meteorol. Soc., 79, 831-844, 1998.

Ichoku, C., Levy, R., Kaufman, Y. J., Remer, L. A., Li, R. R., Martins, V. J., Holben, B. N., Abuhassan, N., Slutsker, I., Eck, T. F., and Pietras, C.: Analysis of the performance characteristics of the five-channel MICROTOPS II sun photometer for measuring Aerosol Optical Thickness and precipitable water vapor, J. Geophys. Res., 107, D13, doi:10.1029/2001jd001302, 2002.

Kassianov, E. I., Flynn, C. J., Ackerman, T. P., and Barnard, J. C.: Aerosol single-scattering albedo and asymmetry parameter from MFRSR observations during the ARM Aerosol IOP 2003, Atmos. Chem. Phys., 7, 3341-3351, doi:10.5194/acp-7-3341-2007, 2007.

Madhavan, B. L., Niranjan, K., Sreekanth, V., Sarin, M. M., and Sudheer, A. K.: Aerosol characterization during summer monsoon period over a tropical coastal Indian station, visakhapatnam., J. Geophys. Res., 113, D21208, doi:10.1029/2008JD010272, 2008.
Moorthy, K. K., Pillai, P. S., and Suresh babu, S.: Influence of changes in the prevailing synoptic conditions on the response of aerosol characteristics to land- and sea-breeze circulations at a coastal STATION, Bound.-Lay. Meteorol., 108, 145-161, 2003.

Nair, V. S., Babu, S. S., and Moorthty, K. K.: Spatial distribution and spectral characteristics of aerosol Single scattering albedo over the Bay of Bengal inferred from shipborne measurements, Geophys. Res. Lett., 35, L10806, doi:1029/2008GL033687, 2008.

Niranjan, K., Malleswara Rao, B., Saha, A., and Murty, K. S. R.: Aerosol spectral optical depths and size characteristics at a coastal industrial location in India - effect of synoptic and mesoscale weather, Ann. Geophys., 22, 1851-1860, doi:10.5194/angeo-22-1851-2004, 2004.

Niranjan, K., Sreekanth, V., Madhavan, B. L., and Krishna Moorthy, K.,: Wintertime aerosol characteristics at a north Indian site Kharagpur in Indo-Gangetic Plains located at the outflow regions into Bay of Bengal, J. Geophys. Res., 111, D24209, doi:10.1029/2006JD007635, 2006.

Niranjan, K., Madhavan, B. L., and Sreekanth, V.: Micro Pulse LIDAR observation of high altitude aerosol layers at Visakhapatnam located on the east coast of India, Geophys. Res. Lett., 34, L03815, doi:10.1029/2006GL028199, 2007.

Niranjan, K., Sreekanth, V., Madhavan, B. L., Anjana Devi, T., and Spandana, B.: Temporal characteristics of aerosol physical properties at Visakhapatnam on the east coast of India during ICARBSignatures of transport onto Bay of Bengal, J. Earth Syst. Sci., 117(S1), 421-427, 2008.

Ohta, S., Hori, M., Murao, N., Yamagata, S., and Gast, K.,: Chemical and optical properties of lower tropospheric aerosols measured at Mt. Lemmon in Arizona, J. Global Environ. Eng., 2, 67-78, 1996.

Pandithurai, G., Dipu, S., Dani, K. K., Tiwari, S., Bisht, D. S., Devara, P. C. S., and Pinker, R. T.: Aerosol radiative forcing during dust events over New Delhi, India., J. Geophys. Res., 113, D13209, doi:10.1029/2008JD009805, 2008.

Pillai, P. S. and Moorthy, K. K.: Aerosol mass-size distributions at a tropical coastal environment: Response to mesoscale and synoptic processes, Atmos. Environ., 35, 4099-4112, 2001.

Porter, J. N., Miller, M., Pietras, C., and Motell, C.: Ship based sun photometer measurements using Microtops sun photometers, J. Atmos. Oceanic Technol., 18, 765-774, 2001.

Ramachandran, S. and Rajesh, T. A.: Asymmetry parameters in the lower troposphere derived from aircraft measurements of aerosol scattering coefficients over tropical India, J. Geophys. Res., 113, D16212, doi:10.1029/2008JD009795, 2008.

Reid, J. S., Eck, T. F., Christopher, S. A., Hobbs, P. V., and Holben, B.: Use of the Angstrom exponent to estimate the variability of optical and physical properties of aging smoke particles in Brazil, J. Geophys. Res., 104(27), 474-489, 1999.

Russell, P., Kinne, S., and Bergstrom, R.: Aerosol climate effects: Local Radiative forcing and column closure experiments, J. Geophys. Res., 102, 9397-9407, 1997.

Satheesh, S. K. and Lubin, D.: Shortwave versus longwave radiative forcing by Indian Ocean aerosols: Role of Sea- Surface winds, Geophys. Res. Lett., 30(13), 1695, doi:10.1029/2003GL017499, 2003.

Schuster, G. L., Dubovik, O., and Holben, B. N.: Angstrom exponent and bimodal aerosol size distributions, J. Geophys. Res., 
111, D07207, doi:10.1029/2005JD006328, 2006.

Sreekanth, V., Niranjan, K., and Madhavan, B. L.: Radiative Forcing of Black Carbon Over eastern India, Geophys. Res. Lett., 34, L17818, doi:10.1029/2007GL030377, 2007.

Takemura, T., Nakajima, T., Dubovik, O., Holben, B. N., and Kinne, S.: Single scattering albedo and radiative forcing of various aerosol species with a global three dimension model, J. Climate, 15(4), 333-352, 2002.
Wiscombe, W. J. and Grams, G. W.: The backscatter fraction in two- stream approximations, J. Atmos. Sci., 33, 2440-2451, 1976. 